\title{
FOGO PROMETEICO, REFORMA DO PENSAMENTO E O REDIMENSIONAR DAS PRÁTICAS EDUCATIVAS: EMERGEM PERSPECTIVAS DIDÁTICAS A PARTIR DA COMPLEXIDADE E DA TRANSDISCIPLINARIDADE
}

\author{
PROMETHEAN FIRE, THOUGHT REFORM AND THE RESIZE OF THE \\ EDUCATIONAL PRACTICES: EMERGING PERSPECTIVES FOR TEACHING \\ FROM COMPLEXITY AND TRANSDISCIPLINARITY
}

\section{FUEGO DE EL PROMETEO ENCADENADO, REFORMA PENSAMIENTO Y PRÁCTICAS EDUCATIVAS: NUEVAS PERSPECTIVAS PARA LA DIDÁCTICA, COMPLEJIDAD Y TRANSDISCIPLINARIEDAD}

Marilza Vanessa Rosa SUANNO ${ }^{1}$

RESUMO: A intencionalidade do presente artigo é apresentar resultados parciais de pesquisa, que sinalizam características emergentes da didática, em perspectiva complexa e transdisciplinar, fruto de elaborações de professores universitários que dialogam com o paradigma educacional emergente.

Palavras-chave: Educação. Didática. Complexidade. Transdisciplinaridade.

RESUMEN: La intención de este artículo es presentar los resultados parciales que indican las características emergentes de la didáctica en perspectiva compleja y transdisciplinaria, elaboraciones de los maestros en diálogo con el paradigma educativo emergente.

Palabras clave: Educación. Didáctica. Complejidad. La transdisciplinariedad.

SUMMARY: The intent of this article is to present partial search results that signal emerging characteristics of teaching in complex and transdisciplinary perspective, elaborations of academics dialogues with the emerging educational paradigm.

Keywords: Education. Didactic. Complexity. Transdisciplinarity.

\footnotetext{
${ }^{1}$ Professora do quadro efetivo da Universidade Federal de Goiás - UFG e da Universidade Estadual de Goiás UEG. Pedagoga. Mestre em Educação (Universidade de Habana/Cuba e PUC Goiás). Doutorado sanduíche pela Universidade de Barcelona/Espanha. Doutoranda em Educação pela Universidade Católica de Brasília - UCB. Membro do Grupo de Pesquisa Ecologia dos Saberes e Transdisciplinaridade - ECOTRANSD. Membro do Grupo de Pesquisa em Rede Internacional Investigando Escolas Criativas e Inovadoras. E-mail: marilzasuanno@uol.com.br
} 


\section{Introdução}

O presente artigo tem por objetivo apresentar algumas características emergentes da didática complexa e transdisciplinar na educação superior ${ }^{2}$. No entanto, antes de adentrar na especificidade desta discussão é pertinente situar que o trabalho do professor universitário, nas últimas décadas, vem sendo afetado por múltiplos fatores, e principalmente, pelos preceitos neoliberais e pelas novas ordenações do Estado, que tem impactado na precarização do trabalho docente, das condições de trabalho e de remuneração. Assim como, a flexibilização do trabalho, com ampliação das funções exercidas e periódicas submissões da produção docente a rigorosos e múltiplos sistemas avaliativos, dentre outros fatores, que tem afetado de forma substancial o trabalho docente, a concepção de docência e universidade, enfim o lócus do conhecimento, como instituição social, democrática, plural, demanda lutar contra a precarização do trabalho docente e resistir à lógica neoliberal.

Docência, do latim docere, significa ensinar, instruir, mostrar, indicar, dar a entender. "No sentido formal, docência é o trabalho dos professores. Na realidade, estes desempenham um conjunto de funções que ultrapassam as tarefas de ministrar aulas" (VEIGA, 2006), e também ultrapassam o trabalho com pesquisa, extensão e gestão. Em detrimento das atuais políticas educacionais, de orientação nacional e internacional, as funções do professor universitário têm sido amplamente modificadas e as novas atribuições, rotina e tarefas atropelam as efetivas funções, ou seja, extrapolam o trabalho docente. Esses tiveram que incorporar várias atividades, a título de exemplos, a busca por financiamentos, a prestação de contas, o registro de notas e informações no sistema informatizado da universidade, a montagem de equipamentos para viabilizar o trabalho, dentre tantas outras atividades.

E em meio a este contexto, e entre outras tantas crises do século XXI, emergem novos caminhos para compreender e dialogar sobre a realidade e redimensionar as experiências educativas e formativas. Novas concepções, práticas e ações inspiradas no paradigma educacional emergente (MORAES, 1997), na complexidade (MORIN, 1999, 2011) e na transdisciplinaridade. Este novos caminhos atuam na contramão de processos hegemônicos e

\footnotetext{
${ }^{2}$ Identificadas na pesquisa, em andamento, Trabalho docente e pedagogia universitária sob a ótica do pensamento complexo e da transdisciplinaridade aprovada pelo Comitê de Ética da Universidade Federal de Goiás - UFG, no 331/10.
} 
neoliberais, que minimizam as questões educacionais à prestação de serviços, sem assegurar que essa seja um direito do cidadão e dever do Estado.

As reflexões em torno do paradigma educacional emergente impulsionam a valorização: a) da reforma do pensamento; b) da criação de novas relações com o conhecimento e entre os conhecimentos historicamente sistematizados e outros; c) do conhecimento pedagógico e o conhecimento didático; d) das relações humanas, o diálogo; e) do processo de ensino e aprendizagem que possibilita pensamento complexo construindo relações e conexões entre os saberes disciplinares promovendo cooperação interdisciplinar e a transdisciplinar como potenciais possibilidades de uma educação emancipadora, multidimensional, multirreferencial, solidária, cooperativa, criativa e amorosa (SANTOS, 2000; MORAES, 2008).

Emerge uma educação humanizadora e complexa que intencionada ensinar: o diálogo; a compreensão; a diversidade cultural e a pluralidade dos indivíduos; a cidadania planetária; a dialógica democrática; a ética; a justiça social; a condição humana; o conhecimento pertinente e complexo, que seja crítico, histórico, social, ambiental e autopoiético; a capacidade de indignar-se e comprometer-se com a transformação de si mesmo e do mundo; a formação do humano autônomo, emancipado, solidário, cooperativo e consciente.

Nesta perspectiva, conteúdo e forma do processo de ensinar e aprender se redimensionam, por meio de um modo de pensar complexo, ecossistêmico e transdisciplinar, que intenciona superar, ou complementar, a perspectiva disciplinar, fragmentada, simplista e hiperespecializada.

Morin (2000) reafirma a relevância da didática e argumenta que a grande inimiga da compreensão é a falta de preocupação em ensiná-la. O que tem agravado o individualismo, o egocentrismo, o egoísmo e que, consequentemente, alimenta a autojustificação e a rejeição do outro, do coletivo e do bem comum.

A complexidade emerge como um pressuposto da docência, e esta última passa a ser compreendida como uma atividade complexa, multidimensional, multirreferencial e autopoiética a ser inventada e reinventada pelo ser humano constantemente. 


\section{Paradigma educacional emergente, complexidade e transdisciplinaridade como "Pensamento-Pimenta"}

As pimentas são frutinhas coloridas que têm poder para provocar incêndio na boca. Algumas ideias são como pimentas, podem provocar incêndio no pensamento. E para provocar incêndio basta uma única faísca. Rubem Alves (2012) brincava com as palavras e ao propor a expressão pensamento-pimenta o faz insinuando, que para provocar incêndio basta uma única faísca.

O paradigma educacional emergente e docência transdisciplinar (MORAES, 1997), o pensamento complexo (MORIN, 1999, 2011), a transdisciplinaridade (NICOLESCU, 1999; MORAES, 2008; SANTOS, 2003; BEHERES, 2003) são pensamentos-pimenta, que podem mobilizar os professores para a reforma do pensamento e da prática educativa criando possibilidades para a transformação da Educação, pois têm a intenção de provocar metamorfoses (MORIN, 2011) no nosso modo de pensar, na nossa relação com o conhecimento e no nosso estilo de vida. E para transformar a educação e ampliar o seu alcance formativo é preciso interrogar nossas certezas, verdades e rotinas. É preciso pensamento-pimenta e uma faísca basta. Mas, onde há faísca, há fogo.

O fogo é uma reação química, em cadeia, produzida pela combinação proporcional $^{3}$ dos elementos essenciais: calor, oxigênio e combustível. O calor é a energia de ativação necessária para que ocorra o fogo. O oxigênio é necessário para a combustão. O combustível é o elemento que serve de propagação do fogo e é capaz de queimar e alimentar a combustão. A reação em cadeia torna a queima autossustentável, um ciclo constante, até que se esgote.

Nas práticas educativas não basta ter os elementos essenciais do processo de ensino e aprendizagem se não houver combinação, interação, mediação, reação em cadeia, autossustentação, diálogo e intencionalidades claras. Insinuo aqui que não estamos cuidando da proporcionalidade, das conexões, das relações necessárias para provocar reações transformadoras do modo de pensar, dos modos de ensinar, aprender e criar cursos de

\footnotetext{
${ }^{3}$ A configuração desordenada desses três elementos (calor, oxigênio e combustível) não produzirá o fogo. Leis das Proporções Definidas ou Leis de Proust (1794).
} 
formação humana capazes de transformar a atual condição humana e a realidade local e planetária.

Somos seres históricos, culturais, biológicos, corporais, psicológicos, sociais, coletivos, pessoais, imaginativos e enigmáticos. Assim, nas práticas educativas é necessário cuidar da proporcionalmente, ou seja, da multidimensionalidade da formação humana. Não somos só cognição. Não somos só mente e inteligência. A ampliação da concepção de sujeito poderá viabilizar um modo de educar que relacione teoria, prática e experiência autorreferencial do sujeito para sentir, pensar, agir e inovar comprometido com cuidado de si, do social, do ambiental e do cósmico.

Ao cuidar da mente há de se oportunizar a aprendizagem de conhecimentos científicos historicamente sistematizados, uma vez que estes são um direito do cidadão e contribuem na possibilidade de igualdade de ascensão social e econômica na sociedade do conhecimento e do trabalho. Mas, complementarmente e simultaneamente, ao cuidar da mente, há de se cuidar da ampliação da consciência, ampliação da percepção, da sensibilidade, do equilíbrio psíquico, do cultivo da empatia, do respeito, da tranquilidade e da resiliência. A mente aprende, ampliadamente, mais que conhecimentos sistematizados. Aprende sobre si mesma, sobre suas reações, suas relações e atitudes. O autoconhecimento pode fortalecer a construção da cultura de paz, do bem viver, da felicidade para além da alegria instantânea e fugaz do consumo, e estas são contribuições formativas necessárias no século XXI. E a educação pode auxiliar neste sentido.

Educar, em perspectiva complexa e transdisciplinar, demanda reforma do pensamento e ampliação dos níveis cognitivos, lógicos, relacionais, meditacionais; dos níveis de sensibilidade e de percepção; dos níveis de compromisso com a própria existência, com o social, com o ambiental; dos níveis de organização coletiva e de criação de ações transformadoras; dos níveis de educação corporal e do movimento; da compreensão dos níveis de realidade.

A transdisciplinaridade nos convida para construirmos outro modo de pensar que tenha novas relações e ações, novos princípios e sentimentos. O convite é para pensarmos 
complexo e religarmos conhecimentos que se encontram fragmentados em disciplinas. E religar a estes, os saberes da experiência de vida. E agregar a estes saberes já religados a sensibilidade perceptiva, representativa e estética, presentes na literatura, na música, na cultura local, global e planetária. Ao religar conhecimentos e saberes, mantemos compreensão da especificidade e riqueza das partes em sua relação com a totalidade.

Alegoricamente as pimentas provocam incêndio nas nossas bocas e os pensamentospimenta incendeiam nossas mentes. Mas de onde vem a faísca? E o fogo?

Na mitologia grega e na obra Prometeu Acorrentado de Ésquilo (525 a.C.- 456 a.C) o herói Prometeu e seu irmão, filhos de um titã, foram responsáveis pela criação dos animais e dos seres humanos, tendo atribuído características e predicados a cada uma das criações.

Quando da criação dos seres humanos na Terra, em um ato de amor, Prometeu ludibriou Zeus, o Deus dos deuses, e roubou do céu o fogo para dar de presente à humanidade, aos mortais. Prometeu conferira o conhecimento do fogo e um toque de inventividade para seu uso. Para Sottomayor (2001) o fogo, ao surgir no mundo, dissipou as trevas e trouxe aos Homens a luz da civilização e da esperança. Conforme Jaeger (2010) Prometeu é o que o traz a luz à Humanidade sofredora. O fogo, essa força divina, torna-se assim o símbolo sensível da cultura, da claridade, da energia produtora de ferramentas, pensamentos, símbolos, arte e cultura.

Com o fogo o homem deixa de ser primitivo e se torna senhor do seu destino, responsável pelas suas ações, e passa a ser algo mais, algo além de uma criação divina. Os mortais passam a fazer história.

Como castigo por seu crime, por ter roubado o fogo e entregue aos seres humanos, Zeus mandou que Prometeu fosse acorrentado no alto de uma rocha com correntes inquebráveis e ali ele deveria permanecer por 30 mil anos. Seu castigo era ter seu fígado devorado diariamente por um abutre, e pela noite, durante o sono, por ser um imortal, ter o fígado reconstituído. Um sofrimento incessante. Todavia, antes de completar este período, Hércules negociou a substituição do castigo. Zeus, afirmara que só libertaria Prometeu se um imortal abrisse mão de sua imortalidade e fosse para o reino dos mortos. Zeus tinha criado 
uma condição que não seria aceita por nenhum imortal. No entanto, Quíron fez o sacrifício voluntário para libertar Prometeu.

Quíron era um centauro (cabeça, tronco e braços de homem e corpo de cavalo) reverenciado como sábio. Tinha sido educador de vários heróis. Era a expressão simbólica do mestre orientador, pois, ao educar, desenvolvia as potencialidades de seus discípulos e cuidava simultaneamente do corpo, do psíquico e do espiritual. Quíron foi ferido acidentalmente por uma flecha envenenada de Hércules, e por ser imortal, ficara vivo. No entanto sofria com dores insuportáveis e incessantes. Por isso desejou a morte e sacrificou-se para libertar Prometeu acorrentado.

O fogo é símbolo da consciência, da criatividade humana. Nos mitos e lendas de várias culturas (grega, inca, povos indígenas) o fogo é reverenciado. No espírito humano arde uma faísca do fogo prometeico, o fogo da esperança criadora.

Na mitologia grega, o fogo entre os mortais deu-lhes perspectivas e os manteve vivos. E na educação, nós, professores, estamos dando o fogo aos nossos alunos? O fogo que os manterá vivos? O fogo que contribuirá para um viver bem? O fogo da esperança e do trabalho para a criação do presente e do futuro? Ou perdemos o fogo? $\mathrm{Ou}$ o fogo foi eliminado?

Existem três formas de eliminar o fogo. A primeira é o resfriamento, quando se retira o calor. O segundo é o abafamento, quando se retira o oxigênio comburente. O terceiro é o isolamento, quando se retira o combustível. Será que nós, professores, fomos resfriados? Abafados? Isolados?

Parece que estamos precisando de pensamento-pimenta, precisando de faísca, de fogo, de incêndio. O curioso e provocativo é que a definição de incêndio é fogo que foge ao controle do homem. Será que o excesso de controle não nos tem permitido incendiar? Mas voltando a Rubem Alves: para provocar um incêndio não é preciso fogo, basta uma faísca, basta um pensamento-pimenta. 


\title{
Didática complexa e transdisciplinar
}

O processo de ensino e aprendizagem, as práticas educativo-formativas, como práticas sociais demandariam de pensamento-pimenta? O fogo queima, mas como sugere outro mito, das próprias cinzas renasce a ave fênix. Assim, no início do século XXI busco identificar uma didática emergente, a didática complexa e transdisciplinar.

Etimologicamente, didática vem do grego: didaktiké, didátikos, do verbo “didasko", que significa instruir, ensinar, expor com clareza. A didática é, simultaneamente, ciência da educação, disciplina pedagógica, campo de investigação e exercício profissional.

A didática, como disciplina pedagógica, tem por conteúdo a sistematização de conhecimentos e práticas referentes aos fundamentos, condições, modos e realização do ensino e da aprendizagem, visando o desenvolvimento das capacidades mentais e afetivas dos alunos (LIBÂNEO, 2007). E simultaneamente articula os conhecimentos a ensinar, os modos de aprender, as relações pedagógicas entre professores e alunos, a convivência solidária, cooperativa e dialógica, que possibilita a mediação no processo de ensino e aprendizagem com potencial para suscitar a ampliação da percepção, da consciência, da aprendizagem e da ação criativa. Libâneo (2012, p.28) compreende que:

\begin{abstract}
a didática reúne em seu conteúdo essas duas dimensões a serviço do processo ensino e aprendizagem: a lógica dos saberes disciplinares e a lógica da relação pedagógica. Permeando estas duas lógicas, introduzo as práticas socioculturais e tudo o mais que aí se deve incluir, a trajetória social dos alunos, a vida cotidiana, as mídias, as identidades sociais e culturais, etc., já que são integrantes das relações pedagógicas. Em outras palavras, a didática é concebida como disciplina que busca melhor compreender como ações de ensino podem gerar ações de aprendizagem, tendo como referência os conteúdos das disciplinas, para propor meios que favoreçam a mútua transição de um a outro. Desse modo, agrada-me hoje falar de uma didática básica [...], uma disciplina que expressaria algo como transdisciplinaridade das didáticas disciplinares.
\end{abstract}

Para Libâneo (2012) a metodologia de ensino mais adequada é aquela que ensina a pensar teoricamente, com os conteúdos e métodos da ciência ensinada. A transdisciplinaridade, ao pensar cientificamente, incorpora subjetividades, cultura, saberes não-científicos e o autoconhecimento. Santos e Sommerman (2014) propõem a complementaridade e coexistência necessária entre ensino disciplinar e ensino transdisciplinar.

A didática, em perspectiva complexa e transdisciplinar, surge em contexto de 
transição paradigmática (MORAES, 1997; SANTOS, 2000), de crises (MORIN, 2011; BRAGA, GENRO e LEITE, 1997), por meio de processos de ruptura, de emancipação e de criatividade (TORRE, MORAES e PUJOL, 2008), pautado na articulação entre reforma do pensamento; reforma da sociedade; reforma da vida; reforma da educação; reforma da universidade; política de humanidade ${ }^{4}$ e política de civilização ${ }^{5}$ (MORIN, 2011).

O pensamento complexo propõe um modo de organizar o pensamento e a ação, por meio de relações e conexões contextualizadas na produção do conhecimento e da emoção via níveis de realidade, níveis de percepção do sujeito, implicados pela subjetividade, objetividade, cultura, natureza e sociedade.

Neste sentido, emergem inovações nas intencionalidades dos professores de pósgraduação entrevistados nesta pesquisa ${ }^{6}$, e estes pretendem rever a finalidade da educação, da formação humana, e construir um trabalho docente inspirado na complexidade e no paradigma educacional emergente. De tal modo, a finalidade da educação passa a ser: promover a reforma do pensamento a fim de possibilitar pensar complexo e transdisciplinar para promover metamorfoses sociais, individuais e antropológica (MORIN, 2011), no intuito de salvaguardar a humanidade, a Terra-Pátria e dar prosseguimento ao processo de hominização (MORIN, 2003).

Os professores entrevistados visam construir práticas de ensino cooperativas e solidárias, autopoiéticas, comprometidas com o presente e o futuro da humanidade, bem como, com potencial e coragem para agir e transformar pessoas, instituições, políticas públicas, enfim a relação homem-natureza-sociedade.

As inovações didáticas identificadas nesta pesquisa foram construídas por meio do trabalho docente por promover a reforma do pensamento (MORIN, 2007), criar práxis complexas e transdisciplinares, em processos de docência transdisciplinar (MORAES, 2008).

\footnotetext{
${ }^{4}$ A política de humanidade pauta-se no humanismo planetário, na governança global, em outra lógica político-econômica capaz de promover simultaneamente processos de globalização e desglobalização; crescimento e decrescimento; desenvolvimento e involução; transformação e conservação.

${ }^{5}$ A política de civilização visa ser capaz de garantir a dignidade humana, a diversidade cultural, e ser capaz de fomentar: política de qualidade de vida; política de convivência; política ecológica; política de solidariedade; por meio da cidadania planetária e da sustentabilidade do planeta.

${ }^{6}$ Este capítulo tem por objetivo apresentar resultados parciais da pesquisa "Trabalho docente e pedagogia universitária sob a ótica do pensamento complexo e da transdisciplinaridade", aprovada pelo Comitê de Ética da Universidade Federal de Goiás - UFG, protocolo n ${ }^{\circ}$ 331/10, e em específico apontar características emergentes da didática transdisciplinar.
} 
A práxis complexa e transdisciplinar constrói-se na relação ternária entre teoria, prática e experiência do sujeito (subjetiva, biográfica, autopoiética), no intuito de criar e promover conhecimentos e ações transformadoras.

Os processos didáticos que emergem são incertos, no entanto, são apostas, que demandam dos sujeitos envolvidos e das instituições uma consciência ampliada sobre o processo formativo, em perspectiva de auto-eco-heteroformação (PINEAU, 2006), e da capacidade de construção de práxis do tipo inventiva (LUCARELLI, 2009) a partir dos princípios operadores do pensamento complexo (MORIN, 2007, MORAES e VALENTE, 2008).

Para Morin (2011a) a mudança nos rumos do capitalismo, é cada vez mais improvável, mas não é impossível. Assim, propõe que pensemos complexo e façamos metamorfoses (transformações com conservação), mas para que isso ocorra é preciso criar outro modo de pensar, outras apostas e estratégias para, talvez, construir outras possibilidades para a vida em sociedade e para a vida no planeta Terra. A universidade e a pós-graduação stricto sensu são convidadas a contribuírem nesse processo de transformação e os docentes entrevistados nesta pesquisa manifestaram a intencionalidade de produzir ruptura paradigmática e construir outras vias para educação e para a vida.

$\mathrm{Na}$ sequência apresento algumas características da didática complexa e transdisciplinar, identificadas até o momento nesta pesquisa, sendo elas: a) reintrodução do sujeito cognoscente; b) pensar complexo; c) transdisciplinaridade; d) ampliação da consciência; e) religar cultura das humanidades e cultura científica; f) conviver com a incerteza cognitiva e a incerteza histórica; g) pensar prospectivo e comprometer-se com o presente e o futuro e h) trabalhar com metatemas, construir metapontos de vista e metaconceitos.

\section{Reintrodução do sujeito cognoscente}

Os operadores ${ }^{7}$ cognitivos do pensamento complexo são a base para se pensar complexo e um destes operadores propõe o princípio de reintrodução do sujeito cognoscente.

\footnotetext{
${ }^{7}$ Morin (2008) propõe como operadores do pensamento os princípios: a) princípio sistêmico-organizacional, b) princípio hologramático, c) princípio retroativo, d) princípio recursivo, e) princípio dialógico, f) princípio auto-eco-organizador ou autoprodução e g) princípio da 
Tal princípio assume uma perspectiva autopoiética e compreende o sujeito como homo sapiens, faber, demens, ludens e mythologicus (MORIN, 2008), ou seja, sujeito complexo, multidimensional, sujeito de razão e de emoção, sujeito histórico, social, cultural, mas também sujeito biológico, cognitivo, pleno de subjetividade, psicoafetivo e enigmático. $\mathrm{O}$ pensamento complexo rompe com a lógica positivista que valoriza em demasia a objetividade, a neutralidade, a impessoalidade. Assim, na perspectiva complexa, as histórias de vida, os processos autorreferenciais e multirreferencialidade são significativos nos processos de construção do conhecimento e na aprendizagem (MORAES, 2010).

O princípio da reintrodução do sujeito cognoscente compreende a inseparabilidade entre ser e conhecer e o papel dinâmico e ativo do sujeito na construção de mediações, relações, intercâmbios, conexões, auto-eco-organizadoras do conhecimento que constrói. "Com a complexidade, resgata-se o sujeito, autor de sua história e coautor de construções coletivas, reintegrando-o ao processo de construção do conhecimento" (MORAES, 2008, p. 106).

O ser humano, nessa perspectiva, é considerado em sua complexidade e o conhecimento produzido pelo mesmo é obra de uma bioantropologia (MORIN, 2000, 2004, 2010). Nesta perspectiva, o conhecimento é construído pelo sujeito complexo e multidimensional a partir de seu nível de percepção, de consciência, de interpretação, e de suas possibilidades de comunicação, de expressão e de linguagem. Assim, todo conhecimento é uma reconstrução/tradução do sujeito numa cultura e num tempo determinado. Dito de outra forma: "Toda realidade se manifesta a partir do que o sujeito é capaz de ver, de reconhecer, de interpretar, de construir/desconstruir e reconstruir em relação ao conhecimento" (MORAES, 2008, p.106).

Nesta pesquisa a entrevistada $\mathrm{X}$ relatou que os sentidos e significados dos conceitos da Epistemologia da Complexidade fertilizaram o seu ser e o seu saber, e lhe permitiram construir outro nível de consciência. Neste mesmo sentido, o entrevistado J analisa que todo conhecimento é autoconhecimento e condição para se viver. E que a relação com o conhecimento é redimensionada, pois há uma relação integradora entre o pensar, o ser e o agir. Talvez por isso, alguns entrevistados externaram sentimentos de prazer e de satisfação na

reintrodução do sujeito cognoscente no processo de construção do conhecimento. Moraes e Valente (2008, p. 9-10) propõem mais três princípios: a) princípio ecológico da ação, b) princípio da enação e c) princípio ético. 
relação interpessoal, na aventura pelo conhecimento nos processos de ensino e de orientação de pesquisas na pós-graduação stricto sensu. Esses mesmo entrevistados, contraditoriamente e complementarmente destacaram que o trabalho docente é árduo, com muitas implicações e dificuldades.

Alguns entrevistados manifestaram que por valorizarem o princípio de reintrodução do sujeito cognoscente e a autopoiese, desenvolvem com os pós-graduandos reflexões auto-ecoheteroformativas; utilizam metodologias de ensino dialógicas e cooperativas; trabalham com pesquisas e narrativas contextualizadas (sujeito, percepções de níveis de realidade, cultural, relações e contexto) por compreenderem o conhecimento como autoconhecimento contextualizado.

Os processos de ensino intencionam mobilizar o pós-graduando para a metacognição, a ampliação da consciência, a sensibilização do ser humano, a articulação entre razão, emoção e corporeidade, de modo que a percepção do sujeito seja aguçada, assim como a sua potencialidade de criar inovações, ou seja, ações transformadoras do ser e da realidade.

\section{Pensar complexo}

Nesta pesquisa foi possível perceber a importância dos princípios operadores do pensamento complexo na estruturação da reforma do pensamento proposta por Edgar Morin. A Epistemologia da Complexidade e a transdisciplinaridade são apresentadas, pelos entrevistados desta pesquisa, como desafio na relação com o conhecimento, na atividade de pesquisa, nos processos de ensino, mas também na relação com a vida e com o meio. Assim como, uma possibilidade para a reforma da educação e a reforma da universidade.

Para Morin (2009) a reforma universitária deve ser uma reforma paradigmática, reforma do pensamento, para tanto, é imprescindível ir além da organização disciplinar e da formação técnica e profissional. Isso significa dizer que, complementarmente à disciplinaridade é preciso reorganizar o conhecimento, hoje disperso, disjunto construindo perspectivas didáticas e de pesquisa rumo à interdisciplinaridade e à transdisciplinaridade, 
religando cultura científica e cultura humanista.

A Epistemologia da Complexidade compreende a realidade como sendo multidimensional dada sua constituição complexa (todo e partes) e o conhecimento construído como uma reconstrução do sujeito por meio de seu nível de percepção da realidade. Deste modo, os entrevistados desta pesquisa intencionam, na perspectiva da complexidade, que ao se analisar uma temática (de estudo ou de pesquisa) sejam religadas diferentes dimensões que a constitui, a fim de contribuir para uma compreensão sistêmica, organizacional, hologramática, dialógica, recursiva e retroativa sobre a mesma. E para tal, múltiplas referências podem ser necessárias para a compreensão da complexidade do objeto. Moraes (2010) apresenta que os fenômenos precisam ser compreendidos na sua multidimensionalidade, observando a multicausalidade e a multirreferencialidade ocorrentes, procurando compreender as relações, as conexões e os vínculos mais importantes. Isto pressupõe também a necessidade de se trabalhar a multidimensionalidade humana a partir de estratégias de aprendizagem que envolvam não apenas os aspectos racionais, técnicos e simbólicos, mas também os aspectos intuitivo, mítico, mágico, afetivo, as múltiplas linguagens que dão sentido e significado a existência humana.

A passagem de um nível de realidade para outro ocorre a partir de processos auto-ecoorganizadores, que possibilitem a ampliação dos níveis de consciência dos sujeitos, visto que existe uma correspondência entre níveis de realidade e níveis de percepção, assim como entre os níveis de percepção e níveis de consciência.

\section{Transdisciplinaridade}

A transdisciplinaridade é uma corrente de pensamento que busca construir novos modos de compreensão da complexidade que se manifesta na contemporaneidade. A transdisciplinaridade incorpora a interdisciplinaridade e caracteriza-se por ir além das relações do campo disciplinar ao incorporar e valorizar diferentes formas de saber (experienciais, filosóficos, culturais, tradições, mitos, lendas...). A transdisciplinaridade relaciona-se com a complexidade humana e suas representações. 
A docência transdisciplinar pauta-se em princípios epistemológicos, ontológicos e metodológicos e se propõe a produzir conhecimento, rever a formação humana, o estilo e sentido da vida, e assim, ampliar a consciência do sujeito na relação homem, natureza e sociedade. Este modo de pensar ecologizante visa ampliar a compreensão do sujeito sobre si mesmo e sobre a complexidade e a pluralidade de representações de mundo. Este é um movimento de reforma do pensamento.

$\mathrm{Na}$ análise das entrevistas desta pesquisa foi possível compreender que há uma relação recursiva, complementar e coprodutora entre complexidade e transdisciplinaridade. Como podemos observar na fala dos entrevistados: "Ao utilizar os operadores cognitivos do pensamento complexo se promove a transdisciplinaridade (Entrevistado S)". "Para promover a transdisciplinaridade é preciso promover o pensamento complexo proposto por Edgar Morin (Entrevistada V)".

Em concordância com o exposto, Petraglia (2008, p. 83) apresenta que "a transdisciplinaridade é fruto do paradigma da complexidade, fundamentada por uma epistemologia da complexidade, também estando presentes em seu seio as interligações de sujeito-objeto-ambiente".

A transdisciplinaridade, segundo Nicolescu (1999), diz respeito àquilo que está ao mesmo tempo entre as disciplinas, através das diferentes disciplinas, além de qualquer disciplina. E tem por pilar os níveis de realidade, a lógica do terceiro incluído e a complexidade.

A entrevistada $\mathrm{Y}$ destaca o potencial da transdisciplinaridade para transformar a realidade, pois transforma as pessoas e os seus valores. Já o entrevistado $\mathrm{H}$ pontua que a transdisciplinaridade tem potencial para favorecer a ampliação da consciência, da visão e da atitude do sujeito. O Entrevistado W, assim como a entrevistada I destacaram que a transdisciplinaridade é um desafio, e para o entrevistado $\mathrm{S}$ é uma inspiração. O entrevistado L declara que:

A transdisciplinaridade alterou a minha didática, posto que a transdisciplinaridade me alterou. A transdisciplinaridade me trouxe reflexões sobre a vida como um todo e a vida como um todo repercute na didática que faz parte dessa vida. A didática sob a ótica do pensamento redutor implica a uma compreensão de ensino e de aprendizagem muito aquém do que podemos ter quando a didática é praticada sob a ótica do que estamos chamando transdisciplinar (Entrevistado L). 
A transdisciplinaridade tem um potencial construtivo e transformador, pois ao transcender as disciplinas as incorpora, assim como rompe com a linearidade e a fragmentação do conhecimento. A transdisciplinaridade tem a pretensão de religar conhecimentos (a partir da articulação de conceitos, noções, enfoque...) a fim de compreender a complexidade do real e assim construir um novo corpo de saber que atravessa, reorganiza e ressignifica os conhecimentos religados. Desta forma, a transdisciplinaridade demanda pulsão religadora, interação, dinamismo e criatividade do sujeito.

\section{Ampliação da consciência}

A principal inovação didática, na perspectiva do pensamento complexo e da transdisciplinaridade, é a busca pela ampliação da consciência do sujeito na relação com o objeto e com a vida, argumenta a entrevistada R. Nesta mesma perspectiva, o entrevistado H argumenta que a ampliação da consciência torna-se conceito nuclear para se pensar a didática transdisciplinar, pois intenciona a ampliação da percepção dos sujeitos sobre si mesmo, assim como sobre os fenômenos. Desta forma:

As inovações não são instrumentais ou metodológicas senão de visão, de estratégia e de avaliação. Afeta o currículo no seu conjunto e ao enfoque dos conteúdos. Procura-se não só que o estudante aprenda a pensar, como também a sentir e a valorizar. (Entrevistado $\mathrm{H})$.

Promover estratégia didática de sentipensar pode contribuir para a ampliação da consciência do sujeito, visto que articula razão, emoção e corporeidade. Sentipensar é um conceito elaborado por Moraes e Torre (2004). Compreendo, a partir deste conceito, que caberia ao professor pensar estratégias de ensino que mobilize os alunos para sentir e pensar simultaneamente, ou seja, trabalhar conjuntamente razão, emoção.

A Entrevistada O apresenta que a partir dos estudos da complexidade e da transdisciplinaridade pode vislumbrar quatro tipos de consciência: a) Consciência de si como ser humano (autoconhecimento); b) Consciência do todo (interdependência); c) Consciência da necessidade de abertura do olhar e da atitude (diálogo); d) Consciência da necessidade de integrar fenômenos e situações aparentemente antagônicos (integração). 
A ampliação da consciência faz emergir novas relações com o conhecimento, novas relações entre os sujeitos, novas relações com a natureza, novas relações com as culturas, novas relações com a transcendência.

Ao promover a ampliação da consciência pode-se ampliar a percepção dos sujeitos, de modo que se percebam como sujeitos planetários, e assim mobilizá-los para interesses coletivos, qualificados para pensar o bem comum, a dignidade humana, a justiça social, a qualidade de vida, e desta forma, buscar se afastar desses tempos de individualismo, desapego e desamparo social da modernidade líquida (BAUMAN, 2001).

\section{Religar cultura das humanidades e cultura científica}

O pensamento complexo não é solução, mas desafio constante voltado à religação entre a cultura científica e a cultura das humanidades. Não há um receituário para a transdisciplinaridade, mas uma pulsão cognitiva contrária à fragmentação. Não se trata de diabolizar as especialidades, mas inseri-las em contextos mais amplos (Entrevistado S).

A separação entre cultura das humanidades e cultura científica trouxe sérias consequências para a formação humana e para o conhecimento produzido e estas foram agravadas no século XX, como aponta Morin (2003).

A cultura humanística é uma cultura genérica, que, pela via da filosofia, do ensaio, do romance, alimenta a inteligência geral, enfrenta as grandes interrogações humanas, estimula a reflexão sobre o saber e favorece a integração pessoal dos conhecimentos. A cultura científica, bem diferente por natureza, separa as áreas do conhecimento; acarreta admiráveis descobertas, teorias geniais, mas não uma reflexão sobre o destino humano e sobre o futuro da própria ciência (MORIN, 2003, p. 17).

O pensamento complexo propõe a articulação entre cultura humanística e cultura científica para possibilitar a formação de "uma cabeça bem-feita" (MORIN, 2003), que ao invés de acumular conhecimentos, dispõe de aptidão para pensar complexo.

\section{Conviver com a incerteza cognitiva e a incerteza histórica}

\footnotetext{
${ }^{8}$ A expressão "Uma cabeça bem-feita" é uma alusão e redimensionamento da formulação de Montaigne, que propôs como finalidade do ensino "uma cabeça bem-feita que bem cheia" (MORIN, 2003).
} 
Outro desafio transdisciplinar é construir ambientes de aprendizagem e de pesquisa, que possibilitem conviver com a incerteza cognitiva e a incerteza histórica.

De acordo com Morin (2003, p. 59) a condição humana é marcada pela incerteza cognitiva e pela incerteza histórica. E argumenta que, há três princípios de incerteza no conhecimento: o primeiro é cerebral: o conhecimento nunca é um reflexo do real, mas sempre tradução e construção, isto é, comporta risco de erro; o segundo é físico: o conhecimento dos fatos é sempre tributário da interpretação; o terceiro é epistemológico: decorre da crise dos fundamentos da certeza, em filosofia (a partir de Nietzsche), depois em ciência (a partir de Bachelard e Popper). Conhecer e pensar não é chegar a uma verdade absolutamente certa, mas dialogar com a incerteza.

Para Morin (2003) além da incerteza do conhecimento convivemos com a incerteza histórica e o inesperado, pois não é possível ter certezas sobre o curso da história da humanidade. Para Morin os grandes acontecimentos do século passado foram inesperados (Primeira Guerra Mundial, Revolução Soviética, queda do Muro de Berlim, colapso do império soviético, dentre outros), por isso "ninguém pode predizer o amanhã (MORIN, 2003, p. 61)".

Bauman (2001) analisa que o projeto da modernidade apresenta-se como inadequado para enfrentar as incertezas do mundo atual, da modernidade líquida. Neste mesmo sentido, Santos (2000) compreende que o contexto de transição paradigmática pelo qual passamos se arquiteta em ambiente de incertezas, complexidade e caos e tem ampla repercussão (nas estruturas, práticas sociais, instituições, ideologias, representações sociais, inteligibilidade, vida cotidiana e na personalidade).

Braga, Genro e Leite (1997) argumentam que inovações se geram em contexto de incerteza paradigmática, contexto no qual, rompe-se com os paradigmas tradicionais, com a racionalidade cognitivo-instrumental, sobrepõe-se outras racionalidades, como cognitivoafetiva e, como propõe Santos (1989,1994), estético-expressiva e moral-prática, reconfigurando os saberes científicos, as humanidades e o senso comum, reconfigurando também as relações de poder. 


\section{Pensar prospectivo e comprometer-se com o presente e o futuro}

No meu trabalho como professora universitária motivo os meus acadêmicos e orientandos no sentido de aprenderem a pensar de forma sistêmica, relacional, processual, e pensar possibilidades, pensar prospectivo, buscar antecipar os fatos; aprender também a envolver-se, preocupar-se, comprometer-se com seriedade e responsabilidade com aquilo que estuda e investiga (Entrevistada U).

Da fala da entrevistada U é possível analisar que a didática transdisciplinar articula-se ao pensamento prospectivo, ao pensamento pró-ativo. Como diria Hessel (2011) é preciso educar para ver o que se passa no planeta Terra, e assim indignar-se e comprometer-se com sua transformação. E como diria Morin (2011a) é preciso criar metamorfoses, ou seja, ações, processos, práticas transformadoras da realidade com a qual nos indignamos.

Complementarmente ao exposto, apresenta-se como significativo considerar a importância de se promover transformações nas organizações, nas instituições universitárias, como orienta o entrevistado B. Nesse mesmo sentido, a Entrevistada I propõe a discussão e a revisão do papel da universidade na sociedade atual, assim como o tipo de formação que esta oferece.

\section{Trabalhar com metatemas e construir metapontos de vista e metaconceitos}

As entrevistadas C e Y compreendem que para ensinar a pensar complexo, uma via inovadora, é religar conhecimentos e saberes em torno de metatemas. A entrevistada Q compreende que o estudo de metatemas favorece a construção de metapontos de vista, que se expressam na elaboração de metaconceitos:

\footnotetext{
Empenho-me em auxiliar os pós-graduandos a construir metapontos de vista sobre o homem, a terra, a vida, a natureza e o cosmo. O que requer leituras antropológicas, filosóficas, poéticas, biológicas, históricas... É um esforço cognitivo articulador, é preciso transitar entre as áreas para ir além delas. Com frequência pedimos ajuda de especialista para aprofundar em temas específicos, nos imbuímos da articulação e da busca pela totalidade (Entrevistada Q).
}

Morin propõe a articulação das disciplinas em torno de metatemas e orienta que "devemos aprender que a procura da verdade pede a busca e a elaboração de metapontos de vista (MORIN, 2010, p. 29)". 
Neste sentido, complementarmente aos conteúdos disciplinares já trabalhados nas universidades, a presente pesquisa me permitiu compreender a relevância do estudo e do diálogo transdisciplinar sobre metatemas, como: mundo, terra, vida, humanidade, arte, história, conhecimento, culturas adolescentes, antropolítica, antropoética, democracia, sustentabilidade, cidadania, consciência, responsabilidade planetária, justiça e responsabilidade social, solidariedade, pluralidade cultural, diversidade, globalização, cultura de paz e não-violência, direitos humanos, pensamento sistêmico, transdisciplinaridade, condição humana, dentre outros.

Por meio do estudo de metatemas, na perspectiva interdisciplinar/ transdisciplinar, desenvolver a capacidade humana de pensar complexo, assim como, ampliar a percepção e a sensibilidade do sujeito sobre as questões humanas, sociais e ambientais. E assim impulsionar a relação entre teoria e prática, com consciência ampliada, comprometimento, criatividade propositiva, atitude transdisciplinar, na elaboração e efetivação de ações transformadoras do real e do sujeito.

Pensar complexo demanda compreender o objeto de estudo e seus respectivos vínculos e relações, para assim, buscar captar sua dinâmica sistêmica-organizacional, recursiva, retroativa e não-linear. Neste sentido, compreende-se que as metodologias de ensino devam ser interativas e auto-eco-organizadoras de modo a favorecer a articulação de dimensões e referências.

A título de exemplo, uma estratégia didática poderia ser construída por meio da utilização de mapas conceituais, da organização de ideias em redes, com a intenção de se criar uma visualização sistêmica, hologramática, recursiva, retroativa e dialógica da temática em estudo. A entrevistada Y narra que em suas aulas utiliza de mapas conceituais, pois: "Os mapas conceituais me auxiliam na tentativa de fundir as perspectivas, as dimensões em torno do metatema de estudo".

Os mapas conceituais são representações gráficas de conhecimentos organizados de forma articulada, e assim, favorecem a visualização dos conceitos, das interações, das dimensões e possibilita a percepção da dinâmica dos conhecimentos religados.

A representação visual de ideias e de suas dinâmicas de interação (fluxos, recursões, retroações, circuitos) atende a finalidade didática de construção do conhecimento transdisciplinar. Essas representações visuais são compreendidas como elaborações 
provisórias, incertas e vinculadas aos níveis de percepção da realidade, de inserção do terceiro incluído, que naquela elaboração foi possível articular e representar.

\section{Considerações provisórias}

Neste texto tive por intuito apresentar algumas considerações preliminares sobre didática complexa e transdisciplinar emergente. E, destacar as intencionalidades docentes, didático-pedagógicas, de suscitar nos processos de ensino e de aprendizagem a criação de novos modos de pensar por meio de novas relações entre sujeitos, teorias e práticas na construção de conhecimentos, atitudes e ações transformadoras ao:

- reintroduzir o sujeito cognoscente na produção do conhecimento e na transformação do estilo de vida;

- auto-eco-organizar processos de ensino e compreensões por meio do modo de pensar complexo (multidimensional, multirreferencial, autorreferencial);

- criar metodologias transdisciplinares que produzam a ecologia dos saberes e suscite ambientes de aprendizagens saudáveis, dialógicos, colaborativos, que valorizem o trabalho coletivo, a autonomia e a ampliação da consciência.

- religar cultura das humanidades e cultura científica;

- conviver com a incerteza cognitiva e a incerteza histórica;

- pensar prospectivo e comprometer-se com o presente e o futuro;

- trabalhar com metatemas mobilizando o ensino com pesquisa em torno da problematização e da transdisciplinaridade, a fim de construir metapontos de vista e metaconceitos.

A didática, simultaneamente, ciência da educação, disciplina pedagógica, campo de investigação e exercício profissional tem sido convidada a dialogar com o paradigma educacional emergente, o pensamento complexo e a transdisciplinaridade, e vem assim, ampliando olhares, perspectivas e possibilidades para transformar pessoas, conhecimentos, processos didáticos, ambientes escolares, relações com o conhecimento e com a vida, e assim, busca contribuir para promover a metamorfose social, individual e antropológica (MORIN, 2011). O paradigma educacional emergente, a complexidade e a transdisciplinaridade 
apresentam-se como potenciais pensamentos-pimenta, como possibilidade e aposta para que com autonomia, diálogo e criatividade os professores, as instituições, os currículos e o Estado possam recriar-se das cinzas como uma fênix, outros processos formativos e outros processos de ensino e aprendizagem que sejam pertinentes para o século XXI.

\section{Referências}

ALANIZ, Anna Gicelle Garcia. Prometeu. https://www.youtube.com/watch?v=kCKdKeohm8. Acesso em 01/10/2014.

ALVES, Rubem. Pimentas para provocar um incêndio, não é preciso fogo. São Paulo: Planeta, 2012.

BAUMAN, Zygmunt. Modernidade Líquida. Jorge Zahar Editor, 2001.

BEHRENS, Marilda. O Paradigma Emergente e a Prática Pedagógica. 3.ed. Curitiba: Champagnat, 2003.

BRAGA, A., GENRO, M. E., LEITE, D. Universidade futurante: inovações entre as certezas do passado e incertezas do futuro. In: LEITE, D., MOROSINI, M. (Org.) Universidade futurante. Campinas: Papirus, 1997.

CUNHA, Maria Isabel da (Org). Pedagogia universitária: energias emancipatórias em tempos neoliberais, Araraquara, S. P: Junqueira e Marin, 2006.

ÉSQUILO. Prometeu Acorrentado. Disponível em: http://www.ebooksbrasil.org/adobeebook/prometeu.pdf. Acesso em 01/10/2014.

HESSEL, Stéphane. ¡Comprometeos! Ya no basta com indignarse. Barcelona: Editora Destino, 2011.

HESSEL, Stéphane. ¡Indignaos! Um alegato contra la indiferencia y a favor de la insurreicción pacífica. Barcelona: Editora Destino, 2011. 
LIBÂNEO, José Carlos. Ensinar e aprender, aprender e ensinar: o lugar da teoria e da prática em didática. In: LIBÂNEO, José Carlos e ALVES, Nilda (Orgs.). Temas de pedagogia: diálogos entre didática e currículo. São Paulo: Cortez, 2012.

LIBÂNEO, José Carlos. Ensino de didática: continua sendo perfumaria? II Encontro de Didática e Prática de Ensino. Anápolis: CEPED, 2007.

LIMA, David Alves de Souza. Téncio-mestre e athelta-heróio: uma leitura simbólica dos mitos de Quíron e do herói entre técnicos de voleibol. Dissertação de mestrado. Escola de Educação Física e Esporte da Universidade de São Paulo. Orientadora Kátia Rúbio. São Paulo, 2012.

LUCARELLI, Elisa. Teoría y prática em la universidad: La innovación em las aulas. Buenos Aires: Miño y Dávila Editora, 2009.

MINDLIN, Betty. O fogo e as chamas dos mitos. Estud. av. [online]. 2002, vol.16, n.44, pp. 149-169. ISSN 0103-4014. Disponível em: http://dx.doi.org/10.1590/S010340142002000100009. Acesso em 01/10/2014.

MORAES, Maria Cândida. Complexidade e currículo: por uma nova relação. Polis, Revista de la Universidad Bolivariana, Volumen 9, $\mathrm{N}^{\circ} 25,2010$, p. 289-311.

MORAES, Maria Cândida. Ecologia dos saberes: complexidade, transdisciplinaridade e educação - novos fundamentos para iluminar novas práticas educacionais. São Paulo: Antakarana/WHH - Willis Harman House, 2008.

MORAES, Maria Cândida. O paradigma educacional emergente. Campinas: Papirus, 1997.

MORAES, Maria Cândida; TORRE, Saturnino de la. Sentipensar: fundamentos e estratégias para reencantar a educação. Petrópolis: Vozes, 2004.

MORAES, Maria Cândida; VALENTE, José Armando. Como pesquisar em educação a partir da complexidade e da transdisciplinaridade? São Paulo: Paulus, 2008.

MORIN, E. Os sete saberes necessários à educação do futuro. São Paulo: Cortez, Brasília: UNESCO, 2000.

MORIN, Edgar. A cabeça bem feita: repensar a reforma, reformar o pensamento. 8. ed. Rio de Janeiro: Bertrand Brasil, 2003.

MORIN, Edgar. Introdução ao pensamento complexo. Tradução Eliane Lisboa. 3.ed. Porto Alegre: Sulinas, 2007.

MORIN, Edgar. La Vía. Para el futuro de la humanidade. Tradução Núria Petit Fontseré. Barcelona: Paidós, 2011.

MORIN, Edgar. O método 3: O conhecimento do conhecimento. Porto Alegre: Sulina, 2008. 
MUSITANO, Manuela. $\mathrm{O}$ homem e o fogo. Disponível em: http://www.invivo.fiocruz.br/cgi/cgilua.exe/sys/start.htm?infoid=1014\&sid=9. Acesso em $01 / 10 / 2014$.

NICOLESCU, Basarab. O manifesto da transdisciplinaridade. São Paulo: Triom, 1999.

PETRAGLIA, Izabel Cristina. Educação complexa para uma nova política de civilização. Educar, Curitiba, n. 32, p. 29-41, Editora UFPR, 2008.

PINEAU, Gaston. Transdisciplinaridade, histórias de vidas, alternância. Articles et chapitres publiés em portugais (2000-2006). Document de recherche $n^{\circ} 18$. Departement des Sciences de I'Éducation et de La Formation. Tours: Université François-Rabelais, 2006.

ROSENFIELD, Kathrin Holzermayr. Édipo entre Priapo e Prometeu. Ágora (Rio J.) [online]. 2005, vol.8, n.1, pp. 9-25. ISSN 1516-1498. http://dx.doi.org/10.1590/S151614982005000100001 . Acesso em 01/10/2014.

SANTOS, Akiko e SOMMERMAN, Américo. Ensino disciplinar e transdisciplinar - uma coexistência necessária. Wak: Rio de Janeiro, 2014.

SANTOS, Akiko. Didática sob a ótica do pensamento complexo. Porto Alegre: Sulina, 2003.

SANTOS, Boaventura de Sousa. A crítica da razão indolente: Contra o desperdício da experiência. São Paulo: Cortez, 2000.

SANTOS, Boaventura de Sousa. A universidade no século XXI: para uma reforma democrática e emancipatória da Universidade. São Paulo: Cortez, 2010.

SILVA, Geórgia Sibele Nogueira da e AYRES, José Ricardo de Carvalho Mesquita.O encontro com a morte: à procura do mestre Quíron na formação médica. Rev. bras. educ. med. [online]. 2010, vol.34, n.4, pp. 487-496. ISSN 0100-5502. Disponível em: http://dx.doi.org/10.1590/S0100-55022010000400003. Acesso em 01/10/2014.

SOTTOMAYOR, Ana Paula Quintela. O fogo de Prometeu. Hvmanitas - Vol. LIII (2001). Disponível em: http://www.uc.pt/fluc/eclassicos/publicacoes/ficheiros/humanitas53/05_Sottomayor.pdf. Acesso em: 01/10/2014.

SUANNO, Marilza Vanessa Rosa. Formação docente e didática transdisciplinar: aventura humana pela aventura do conhecimento. In: SUANNO, Marilza V. R.; LIBÂNEO, José Carlos; LIMONTA, Sandra Valéria (Orgs.). Concepções e práticas de ensino num mundo em mudança: diferentes olhares para a didática. Goiânia: CEPED e Editora PUC Goiás, 2011.

TORRE, S. de la; MORAES, M.C.; PUJOL, M. A. Transdisciplinaridade e ecoformação: um novo olhar sobre a educação. São Paulo: TRIOM, 2008.

UNISSINOS. Direito e Literatura - Prometeu Acorrentado, de Ésquilo. Apresentação: Prof. Dr. Lenio Luiz Streck (IHJ) Convidados: Prof. Dr. Dino Del Pino e Prof. Dr. Alfredo Culleton. 
Disponível em: https://www.youtube.com/watch?v=J1ghfA0U16E. Acesso em 01/10/2014.

VEIGA, Ilma Passos Alencastro. Docência Universitária na educação superior. In: RISTOFF, Dilvo; SEVEGNANI, Palmira (Orgs.). Docência na educação superior. Brasília: Instituto Nacional de Estudos e Pesquisas Educacionais Anísio Teixeira, p.85-96, 2006. 